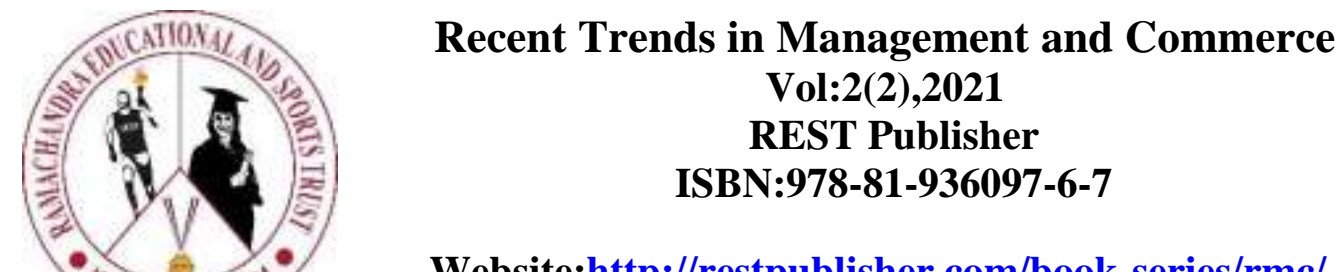

Website:http://restpublisher.com/book-series/rmc/

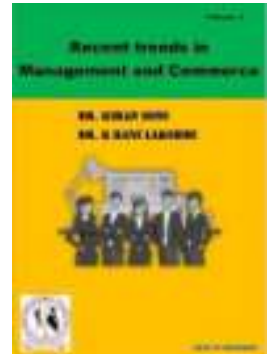

\title{
Impact On Digital Technology On Learning Among Students with Reference to Chennai City
}

\author{
N.saranya \\ Shri shankarlal sundarbai shasun Jain college for women in Chennai, Tamilnadu,India. \\ Email: saranya.narayanan24@gmail.com
}

\begin{abstract}
The use of the internet and other information and communication technologies (ICTs) in higher education locally and globally has been phenomenal. The paper attempts to study the benefits and difficulties faced by students in usage of technology in education. Descriptive statistics were used to assess the demographic variables of students and to know the frequently used technology in learning.
\end{abstract}

Key words: Benefit and difficulties and most frequently used technology.

\section{Introduction}

Information and communication technologies (ICT) is fundamental in the promotion and development of growth in education. Inventions and innovation have led to the increase in tools that are available as educational tools. The tools come in handy in collection of relevant material, storage and dissemination of education material and improvement of quality of delivery and learning.Information and communications technology (ICT) has various set of high-tech tools and resources used for generating, storing, dealing and communicating information to support teaching and learning activities. A technology-based learning offers various interesting ways which includes educational videos, stimulation, and storage of data, the usage of data bases, mind- mapping, guided discovery, brainstorming, music, world wide web (WWW) that will make the learning process more fulfilling and meaningful. On the other hand, students will benefit from ICT tools where they are not limited to the limited curriculum and resources, instead hands - on activities in a technology - based course is designed to help them to stimulate their understanding about the subject. The ICT technology changes the learning style by making the complicated subject and dry units more clear.

Digitalization of Education System

In developing nations such as India, where pupils are plentiful but teachers are rare, this digital revolution appears to be critical. As a result of fast technological progress, the Indian educational system is confronted with a slew of new difficulties and opportunities. The trends of liberalization, privatization, globalization, and easy access have accelerated the growth of digitalization of education, which is critical for the Indian education system, and there has been a rapid in creating preferable goals for education. Technology has advanced to the point where we now live in an information society with no borders, which has the potential to be significant.In today's digital world, it's critical to strengthen computer and information technology skills among higher education stakeholders, as well as their ability to make optimal use of digital resources. There has been a paradigm shift in education systems around the world as a result of the advancement of digital technology in education. It is transitioning from traditional teacher-centered learning to new learner-centered teaching methods. Computers, the internet, and social media are being used by students to learn facts, skills, knowledge, and attitudes. Technology has made a huge effect in a variety of educational procedures.

\section{The Impact of Technology Among Student Engagement}

The use of instructional technology has been shown in numerous studies to improve overall student motivation and engagement in learning. Technology engages students in three ways: behaviorally (greater effort and time spent participating in learning activities); emotionally (positively impacting attitudes and interests toward learning); and intellectually (positively impacting attitudes and interests towards learning) (mental investment to comprehend content). Students have additional possibilities to communicate with instructors, collaborate with peers, and participate in the learning process when technology is included during class time or beyond school hours.

\section{Internet connection and round the clock connectivity}

Over the course of a decade, the internet has increased in importance numerous times. Its significance in the field of education cannot be overstated at this point. Despite the risks of fraud and other disadvantages, kids find that using the internet is a boon. The internet is now integrated into practically all of our daily activities. The internet is absolutely everywhere, from our televisions to our game consoles to our cell phones. Students may discover a lot of aid, tutorials, and other types of helping material on the internet, which they can utilize to boost their academic performance and learning. 


\section{Statement of The Problem}

In today's modern world learning and teaching methods have transformed in a massive way due to advancement in the information technology. The purpose of this study is to examine the students perception on usage in ICT tools in learning practice. The study attempts to identify the benefits and problems faced while using the ICT tools.

\section{Objective of the study}

To analyze the factors which benefit the students through digitalized learning tools. To find the difficulties faced by students through digitalization. To give suggestions to explore various possibilities of implementing the technology in a better way. Hypothesis of the study (null hypothesis) there is no significance difference between the educational qualification and statement with respected to mobile learning. There is no significance difference between the age and effectiveness of learning through digitalization. There is no difference in the respondents on, effectiveness of learning through digitalization. Limitation of the study the data has been collected from the school and college students among chennai city only. The accuracy of the findings of study depends upon the correctness of the respondents. The study has been conducted only on 519 respondents in the city of chennai. Research methodology research design a research design wills typically included how data is to be collected, what instruments will be employed, how the instrument will be used and the indented means for analyzing data collected. A descriptive research was carried out to the impact on digital technology on learning among students. Population the aggregate of all units pertaining to the study is called as population of the universe. The population of this study is covered in the chennai city. Primary data was collected from the population. Sample size in this study the sample size was limited to 519 samples within the chennai limit based on the random sampling technique.

\section{Review of Literature}

Bothmann, holmberg and Schwarzkopf (2005).the study reveals that the archives are struggling to determine how to invest their e-resource dollars to meet the needs of their patrons. During this conference, melissa holmberg and bobby bothmann presented their analysis of two e-journal managing tools: ebsco's ejs and oclc's eco. Their study contrasted the usage of printplus-free-electronic titles at minnesota state university, mankato which are accessed through a fee based and free e-journal management tool. Goncalves, pereira and cota (2010) have studied on "e-sharing development and use of learning objects repository" the study explained that the new learning environments, built width digital technologies, the need to endorse quality of education resources, commonly known as learning objects, which can support formal and informal distance learning, emerge as one of the biggest challenge that educational organizations will have to expression. Owing to the facts that is expensive, the reuse and communicating became very important issue. A learning object source which aims to store, to disseminate and maintain available learning objects. Higgins et al (2012)give a rapid of data from cautious and quasiexperimental educations that have been shared in meta-analyses to assess the impact of digital learning in schools. They obtained 48 studies that combined practical data on the impact of digital tools and resources on school-aged learners' achievement (5-18year olds). Lawal (2006) directed a study on "electronic reference works and library planning dilemma". The study reveals that the number of electronic possessions has climbed up gradually in recent times. Some of these eresources are reference sources, mostly in science, technology and medicine (stm), which originators convert to electronic for understandable reasons. Maximiano, and fernandes (2010) have surveyed on "mobile e-learning: provision services case study". It is found that at present mobile devices and wireless infrastructures are present in the daily tasks of our lives. Mlearning covers the e-learning perception by the use of mobile computation and 33 declaration technological resources. Mobile computing attentions the paradigm of "anytime, anywhere access" that offers resources for distance education via mobile devices. This standard, allows that information is made obtainable to users with greater elasticity and diversity, subsidiary learning in non-conventional places and time schedules.

\section{Conceptual Frame Work}

Orgin of digital technology conventional educational tactics are progressively being replaced by digital learning. Given how quickly classrooms are changing, it's necessary to set aside old teaching and learning methodologies in favour of modern cardinal learning apparatuses and technology. Digital learning can include everything from using tablets instead of paper to using complex software and equipment in the classroom instead of a simple pen. Websites, services, programmes, instructional aids, and technologies like at-home study aids could all be used in this way. Using social media and communication platforms, digital assignments and agendas can be generated and handled. Digital learning has become a crucial component of education, regardless of how much technology is utilised in the classroom. It empowers pupils by encouraging them to learn and expand their perspectives. Here are some ways that digital learning differs from traditional schooling techniques. Around the world, new technological advancements are becoming an integral element of teaching and learning. New technologies are widely believed to have the potential to transform education. Students, in particular, can connect with new media to develop their skills, knowledge, and worldview, all whilebeing supervised by their teachers. For example, e-learning is the assignment of skills and information via a processor and a system. Web-based learning, computerbased learning, virtual education, and digital collaboration are all examples of e-learning applications and procedures. Internet, intranet/extranet, audio or video cassette, satellite TV, and CD.

\section{Current Literature of Digital Learning}

As a result, current literatures demonstrate that domestic and international academics have distinct interpretations for digital learning. By examining the perspectives of numerous researchers in depth, digital learning could be divided into four parts.(1) Digital teaching materials: It highlights that students can learn by pulling content from digital educational materials. The term "digital teaching material contents" refers to e-books, digitalized data, and other digitally presented materials. (2) Copyright@RESTPublisher 
Digital tools: It emphasizes the use of digital technologies such as desktop computers, notebook computers, tablet computers, and smart phones to carry out for learning activities.(3) Digital delivery: It stresses that learners' learning activities can be supplied via the Internet, such as intranets, e.g. the internet, or satellite broadcasting.(4) Autonomous learning: It focuses on learners engaging in online or offline learning activity through digital learning by themselves. It stresses on personal autonomous learning and requires the participation of learners with autonomous learning to precede learning activity.

\section{Emergence of Digital Technology}

Emergence of digital technology could be traced back to the mid of the 19th century; when in 1947 transistors were invented and led the way for the development of more advanced digital computers. In 1951 first commercially available computer was released which was only able to perform arithmetic calculations and simple data handling. In late 1960s, intel developed microprocessors, which pave the way of microcomputers as we see them today. An early precursor of the internet was also introduced in the similar timeframe, in 1969, with the name of Arpanet. In the decade of 1980, computers have started making their place in schools, offices, industries and homes. Cds, mobile phones, digital cameras and video game were also introduced during this decade. The zeitgeist of digital technology was the invention of world wide web (www) in 1989 by tim Berners-Lee. In 1991, www became accessible to introduction 2 public. The decade of 1990 witnessed the prologue of web browsers, smartphones, and Bluetooth technology along with the launch of first social networking site i.e. Sixdegrees.com. A new age of social media began with the birth of Facebook in 2004, followed by youtube in 2005 . Elearning term covering the web-based learning, computer-based learning, and virtual classrooms are all examples of elearning applications and processes. Content can be sent via the internet, intranet, extranet (lan/wan), audio and video tapes, satellite transmission, or cd-rom, among other methods. It is a term that refers to computer-based learning and other supportive resources. E-learning is a method of incorporating information technology into the classroom. Benefits of digital learning over traditional education methods traditional educational approaches are gradually being replaced by digital learning. It is given that how quickly classrooms are changing, it's necessary to set aside of old teaching and learning methodologies in favour of modern digital learning tools and technology. Digital learning can range from utilizing tablets instead of paper to employing complex software programs and equipment instead of a basic pen in the classroom.

\section{Data Analysis and Interpretation}

Mostly use to access the technology, internet for learning technologies open up significant possibilities for supporting learners. Researchers in the field use the term affordance to refer to opportunities that a technology makes possible related to learning and instruction. The following table shows the distribution of the online classes is useful to students of the sample respondents.

TABLE 1. Data Analysis and Interpretation

\begin{tabular}{|l|l|l|}
\hline $\begin{array}{l}\text { Use to access the technology, internet for } \\
\text { learning }\end{array}$ & Frequency & Percent \\
\hline A desktop computer & 116 & 22.4 \\
\hline A smartphone & 206 & 39.7 \\
\hline A laptop & 104 & 20 \\
\hline Mobile phone without computational features & 71 & 13.7 \\
\hline Tablet & 22 & 4.2 \\
\hline Total & $\mathbf{5 1 9}$ & $\mathbf{1 0 0}$ \\
\hline
\end{tabular}

\section{Inference}

It is inferred from the above table that $22.4 \%$ of them are engaged in desktop computer using to access the technology, internet for learning and $39.7 \%$ of them are engaged in smartphone using to access the technology, internet for learning and $20 \%$ of them are engaged in laptop using to access the technology, internet for learning and $13.7 \%$ of them are engaged in mobile phone without computational features using to access the technology, internet for learning and $4.2 \%$ of them are engaged in Tablet using to access the technology, internet for learning. This implies that majority of the respondent are engaged in smartphone using to access the technology, internet for learning.Digital literacy means having the skills you need to live, learn, and work in a society where communication and access to information is increasingly through digital technologies like internet platforms, social media, and mobile devices. The following table shows the distribution of the online classes is useful to students of the sample respondents.digital technology skill

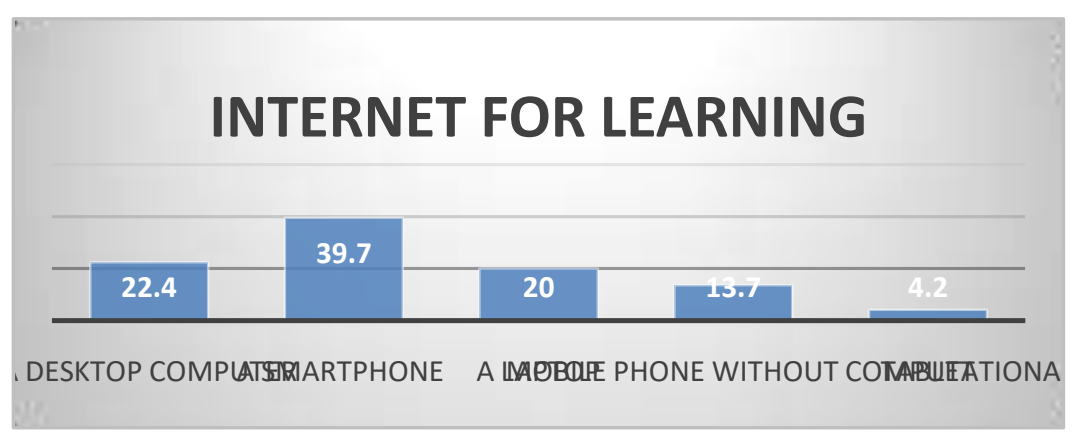

FIGURE 1.Mostly Use to Access the Technology, Internet for Learning 
TABLE 2. Digital technology skill

\begin{tabular}{|l|l|l|}
\hline Digital technology skill & Frequency & Percent \\
\hline Trial and error method & 139 & 26.8 \\
\hline $\begin{array}{l}\text { Guidance from parents, teacher or } \\
\text { neighbors }\end{array}$ & 140 & 27 \\
\hline Learning as a subject in school / college & 167 & 32.2 \\
\hline Attending a certificate courses / workshop & 73 & 14.1 \\
\hline Total & $\mathbf{5 1 9}$ & $\mathbf{1 0 0}$ \\
\hline
\end{tabular}

(Source: primary data)

\section{Inference}

It is inferred from the above table that $26.8 \%$ of them are engaged in trial and error method to acquired digital technology skill and $27 \%$ of them are engaged in guidance from parents, teacher or neighbours and $32.2 \%$ of them are engaged in learning as a subject in school / college and $14.1 \%$ of them are engaged in attending a certificate courses / workshop. This implies that majority of the respondent are engaged in learning as a subject in school / college to acquired digital technology skill.

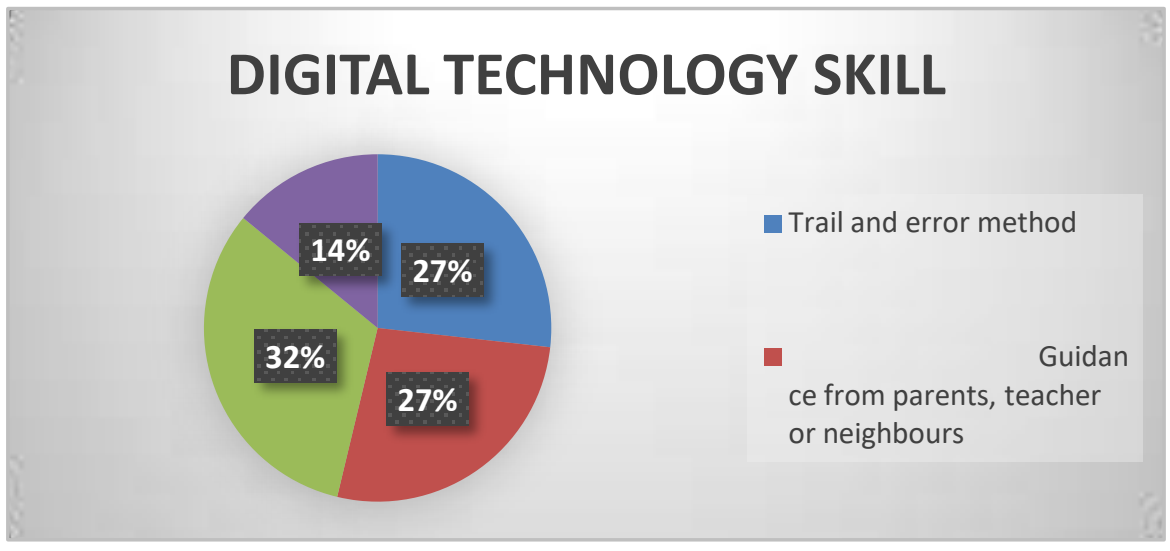

FIGURE2. Acquired Digital Technology Skill through the Respondent

Suggestion to Explore Various Possibilities of Implementing the Technology in A Better Way Finding creative ways to use technology in the classroom can both make your life easier as a teacher and boost student excitement levels and engagement with lessons. From helping with communication among teachers and students (as well as peer-to-peer), to organizing curriculum calendars, to enhancing presentations and lessons with media and visuals, there is no limit to the ways to use technology in the classroom to create an enriched learning environment.

TABLE 3. Suggestion to Explore Various Possibilities of Implementing the Technology in A Better Way

\begin{tabular}{|l|l|l|}
\hline Possibilities of implementing the technology & Frequency & Percent \\
\hline Increased electronic service & 139 & 26.8 \\
\hline Equipment update & 116 & 22.4 \\
\hline Increased integration of the city & 122 & 23.5 \\
\hline Sharing references before the session & 102 & 19.7 \\
\hline Others & 40 & 7.7 \\
\hline Total & $\mathbf{5 1 9}$ & $\mathbf{1 0 0}$ \\
\hline
\end{tabular}

\section{Inference}

It is inferred from the above table that $26.8 \%$ of them are suggesting to increased electronic service to explore various possibilities of implementing the technology and $22.4 \%$ of them are suggesting to equipment update to explore various possibilities of implementing the technology and $23.5 \%$ of them are suggesting to increased integration of the city to explore various possibilities of implementing the technology and $19.7 \%$ of them are suggesting to increased electronic service to explore various possibilities of implementing the technology and $7.7 \%$ of them are suggesting others to explore various possibilities of implementing the technology. This implies that majority of the respondent are suggesting to increased electronic service to explore various possibilities of implementing the technology. 


\section{VARIOUS POSSIBILITIES OF IMPLEMENTING THE TECHNOLOGY}

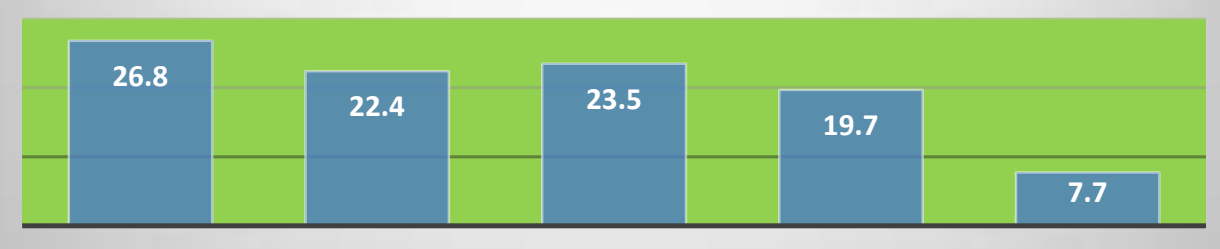

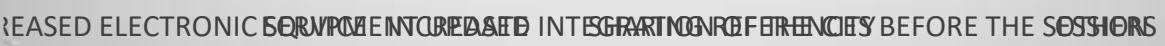

FIGURE 3. Suggestion to Explore Various Possibilities of Implementing the Technology of the Respondent

\section{Findings, Suggestions \& Conclusions}

It is inferred from the table 4.2 that from the sample of 519 respondents, $39.1 \%$ of the respondents were male and $60.9 \%$ were female. This denotes that female respondents are higher when compared to male.It have been concluded that $22.4 \%$ of them are using a desktop computer to access the technology, internet for learning and $39.7 \%$ of them are using a smartphone to access the technology, internet for learning and $20 \%$ of them are using a laptop to access the technology, internet for learning and $13.7 \%$ of them are using mobile phone without computation feature to access the technology, internet for learning and $4.2 \%$ of them are using tablet to access the technology, internet for learning. this implies that majority of the respondent are using a smartphone to access the technology, internet for learning.36.6\% of respondents has implies that majority of the respondent are strongly disagree on using technology in the classroom.49.1\% majority of the respondent are engaged 0-5 hour /week on utilizing technology for homework in school / college.suggestions e-readers should be introduced in class rooms to balance the approach and also to benefit from the latest information available over the internet compare to traditional books where much of the information is outdated.teachers should motivate students to use information technology positively for educational purpose in class room environment. Social media and its applications should be adopted by teachers during the course of their lecture delivery.

\section{CONCLUSION}

The conducted research demonstrated that there is a strong relationship between the use of digital technology and student's behavior. Certainly, the use of mobile applications and technology effects students' behavior, academic performance and teaching strategies. Alternatively, the educational objectives got a direct link between with the use of digital technology in the class room environments. It is impossible to stop students from using digital technology during the course of lecture deliver and therefore teachers need to adopt new techniques and methodologies to balance this and overcome issues raised due to the use of mobile or using any digital applications. The world of e-learning in higher education is in transformation and we need to benefit from the available information technology and applications. This is the responsibility of the teachers to make sure and balance the use of information system and technology during the course of their lecture delivery in class room environments. 